\title{
1. The national defense ecosystem: context, challenges and opportunities
}

\subsection{BACKGROUND}

I tell people all the time to stop saying we're the greatest military in the world. Because what happens is that you start to believe it. (LTG (R) Ed Cardon)

The US Defense sector is a behemoth. It comprises a variety of stakeholders: from the large, publicly traded defense contractors and their suppliers, to numerous firms involved in providing business services, governmental committees and regulatory agencies engaged in guidance, supervision and oversight, and various entities in between. The Defense Acquisition Handbook classifies the entities involved in the acquisition process as follows: end users or operators, depots, acquisition commands, test communities, manpower, personnel and training communities, maintainers and suppliers. At the center of this intricate web is the US Department of Defense (henceforth referred to as DOD), which sets the agenda for defense spending and growth. The DOD conducts its business from over half a million facilities at approximately 4800 sites encompassing close to 25 million acres. It is the nation's largest employer and largest healthcare provider, with over 1.4 million active duty personnel and 1.1 million reservists, and has a budget of over half a trillion dollars for fiscal 2018 (Amadeo, 2018). The scope and involvement of private sector companies in the defense sector is equally profound. In 2016, for example, the top 100 aerospace \& defense (A\&D) companies accounted for $\$ 709$ billion in revenue, resulting in $\$ 69$ billion in profits. In 2018, industry revenues reached $\$ 729$ billion, with an operating profit of $\$ 81$ billion, surpassing previous records set in 2014 and 2017 respectively (PriceWaterhouseCoopers, 2017, 2018).

The United States spends more on its defense budget than China, Saudi Arabia, Russia, the United Kingdom, India, France and Japan combined (Peterson Foundation, 2017). Since 2013, the DOD has accounted for nearly 20 percent of total federal spending. For 2019, Congress allocated $\$ 693$ billion to the DOD. This budget pays for the salaries, training and healthcare of uniformed and civilian personnel, development and procurement of material and facilities, operations and maintenance of the full spectrum of military activi- 
ties, thus funding the four branches of the US Military: the Army, Navy, Air Force, and Marine Corps. The DOD's appetite for goods and services is tremendous, with some studies estimating that US military consumption exceeds 2 percent of the Gross Domestic Product (Borowski, 2015). This formidable size and scale comes with its share of vulnerabilities: new technologies that make old investments obsolete, adversaries who are more nimble and distributed than national militaries, and the ever-changing and asymmetric nature of modern warfare. Recent advances in artificial intelligence (AI), distributed computing, the rise of autonomous vehicles, cyber technologies, and others, are challenging the military's traditional dominance of new technologies and platforms (FitzGerald and Parziale, 2017). Today, it is increasingly clear that no single organization can maintain a monopoly over the cascading stream of technological breakthroughs that drive competitive advantage. Despite its size, the DOD is not exempted from this reality. Through the mid-1980s, the US government accounted for over 50 cents of every R\&D dollar spent worldwide. Today, it accounts for approximately 10 cents of every dollar - even less, if one discounts management overheads and test and evaluation from the R\&D spending totals (National Science Foundation, 2014).

Innovation is a crucial - perhaps the crucial - strategic weapon in the military arsenal. The dominant innovation paradigm in the DOD emerged in the early years of the Cold War and manifested itself in a set of internal organizational competencies and complementary industry structures. Prior to America's entry into World War II, President Franklin D. Roosevelt coined the term "Arsenal of Democracy" to refer to US industrial activity supporting the Allied war effort (Hooks and Bloomquist, 1992). President Dwight D. Eisenhower subsequently named the collection of private firms, universities, and Federally Funded Research and Development Centers that emerged in connection with the World War II arms build-up as the military-industrial complex, and he warned of the moral peril implicit in the alignment of economic and national security interests (Held and McGrew, 2007). Despite President Eisenhower's admonitions, the industry component of the military-industrial complex or what is now commonly known as the Defense Industrial Base (DIB) has grown to become one of the largest sectors of the US economy accounting for nearly 4 percent of GDP - a substantially greater percentage if the impact of military-derived technology such as the Internet is included in the calculation (Levinson et al., 2011). The modern DIB reached the apex of its impact and scale in the Cold War. Its power was not just military, but economic, scientific, technological and cultural. During this period, massive weapon systems development programs led the DOD to evolve a complex, heavily managed, deliberate approach to New Product Development (NPD) that prioritized the elimination of technical and programmatic risk. Confronted with an adversary in the Soviet Union who mirrored a centralized, planning-centric NPD model, 
the DIB successfully built and deployed a wide array of sophisticated military products that played a decisive role in determining the outcome of the Cold War.

After the Cold War and the break-up of the USSR, the US was left as the only remaining superpower. The term "Unipolarity" has been widely employed as a means of capturing conceptually the uniquely powerful position of the US in global politics. With the disintegration of its only significant strategic competitor, America was now the only great power with a global power projection capability (Posen, 2003). Today, however, the national security environment is characterized by an increasingly diverse mix of threats that evolve at the pace of Moore's Law - a concept that refers to the doubling of transistors in a dense integrated circuit every two years (Moore, 1965). One example of the reactive threat phenomenon is Improvised Explosive Devices (IEDs). Constructed from commercially derived components, IEDs began appearing on the battlefields of Iraq and Afghanistan as early as 2002, where they have been responsible for most US combat fatalities (Cordesman et al., 2010). It is generally accepted that the main challenge in mitigating the impact of IEDs is their lack of standardization combined with an NPD cycle that measures in weeks to months. Almost as soon as the US military deploys an IED countermeasure, new IED variants start to appear on the battlefield rendering the countermeasure obsolete. Yet while war encourages expedient adaptation, military organizations present some serious obstacles to any significant and sustained level of user innovation. Would-be user-innovators live in a controlled world of classified information and austere configuration policy intended to limit lethal mistakes and enemy exploitation. Short tours-of-duty and war-fighting responsibilities limit users' ability to support their inventions, and they lack the legitimacy of official acquisition and certification regimes. The defense procurement bureaucracy is notoriously complicated and inefficient: it is plagued by strategic uncertainty, congressional log-rolling, industrial rent-seeking, inter-service competition, and a raft of lawyers, program managers and engineers (Dombrowski and Gholz, 2006).

In the Cold War, the United States derived its military-technology advantage from incremental improvements to existing weapons systems and "going long" on a small number of game-changing technologies with expected operational half-lives measured in years to decades. Under the old rules of innovation, which enabled DOD to build a decisive high-tech edge after World War II, technological competitiveness was generally linked to large capital investments, lengthy development cycles, and strategic forecasting. Today, these same rules no longer apply. DOD has become a relatively minor player in a global research and development marketplace that is increasingly dominated by commercial concerns (Battelle, 2014). In this context, it can no longer rely on dictating or even shaping the technology environment. At the 
same time, globalization and democratization of advanced technology has precipitated a new competitive high-tech landscape characterized by what technology writer Gil Press (2014) describes as Amazon-style innovation: at scale, high-velocity and low-cost. It is interesting to note the changing nature of Amazon itself, and its role in national security and politics. Beyond being the world's biggest online retailer, the company is on the brink of becoming one of America's largest defense contractors. According to some experts, "Amazon wants to neutralize and then displace the traditional Department of Defense vendors and become the 21st-century IBM for the US government" (Weinberger, 2019).

At the macro level, the US National Security Strategy acknowledges an increasingly complex global security environment, characterized by overt threats to the free and open international order and the re-emergence of long-term, strategic competition between nations (Mattis, 2018a). Today, US national security is simultaneously beset by the challenges of a weakening post-World War II international order along with the reemergence of long-term, strategic competition from what the National Security Strategy classifies as revisionist powers (e.g. China and Russia). Moreover, rapid technological advancements fomented by market forces and social and economic instability as a result of shifting cultural norms, urbanization, and population growth presage fundamental changes to the character of war. While states remain the principal actors on the global stage, non-state actors, from transnational corporations to terrorist networks, influence the security environment with increasingly sophisticated capabilities. Combined, these forces imply a level of dynamism and uncertainty that disrupts traditional, industrial-scale military bureaucracies (Department of Defense, Summary of the 2018 National Defense Strategy, 2019). As Sean McFate (2019), a National Defense University professor and former paratrooper, observes in his book The New Rules of War, the current operating model of the defense establishment shows serious signs of what he calls "strategic incompetence". In an age of "durable disorder", characterized by ongoing and omnipresent armed conflicts, he argues that the changing nature of war renders useless traditional concepts of defining the enemy, or understanding the parameters of the war itself (McFate, 2019). Today's adversaries can be stateless, yet achieve popular support; can inflict serious damage without any kind of standing army; and carry out lethal subversive campaigns and covert proxy wars. Today, the very concept of war is fluid, with combatants drifting in and out of conflict, through conventional insurgencies and parries, alongside non-traditional means including psychological warfare achieved through exploitation of social media. He points to a future where the use of special forces, private and mercenary armies, will not only become more widespread, but somewhat inevitable, as traditional power structures and relationships come under increased pressure. This new status 
quo, combined with easy access to the latest technologies, will act as a force multiplier for subversive action by adversaries large and small.

In such a dynamic, competitive environment, it is imperative that forward-thinking governments (and militaries) learn how to view innovation and entrepreneurship on a local, national and global basis. In order to respond to these threats, there is a need for a clear and focused strategy, as well as ways to bring out the best when it comes to finding tactical solutions that can be deployed quickly in the field, and at scale. Success in this context vis-à-vis innovation requires all of the DOD's considerable material and knowledge assets to be aligned, so that they can be deployed not only to counter the latest threat, but also to change the dynamics of the game by creating new capabilities based on advancements in science, technology and the human imagination. Such an outcome, by definition, requires the cultivation of a new strategic mindset, the creation of new institutional capabilities, and a new degree of openness and flexibility. All of these characteristics, on some level, seem antithetical to the very nature of a large, hierarchical and complex enterprise, which is the central challenge of defense technological innovation as it is practiced today.

It must be noted that the economic, technological and societal impacts of the DOD extend far beyond its direct industry constituencies. Beginning in the sixteenth century, the monopolization of military matters in Europe by nation-states and the associated emergence of military science as a means to organize for large-scale conflict laid the foundation for the industrial revolution (Kennedy, 1988). In the US, military imperatives gave rise to the "arsenal system", a network of government-run manufacturing plants and depots developed beginning in the early nineteenth century. The arsenal system is credited with introducing production techniques, including machine manufacturing and interchangeable parts, that eventually revolutionized the face of manufacturing. These production methods would come to be known as the "American System" of manufacturing, which set the stage for the American industrial miracle of the late nineteenth and twentieth centuries (Hounshell, 1985). More recently, the spillover of research and development from the DOD to the civilian world ushered in the information age. It is indisputable that government spending on defense spurred many of the technological breakthroughs of the twentieth century. The DOD technology value chain spans a wide spectrum of activities, including basic and applied research and development; design and manufacture of complex, integrated weapons systems; acquisition and sustainment; and employment-related considerations associated with military doctrine, organization, training and personnel. Military inventions ranging from the Global Positioning System, to the Internet (i.e. ARPANET), to autonomous vehicle technology have come to define the modern high-tech landscape. The DOD, in turn, has benefited from the controlled proliferation 
of technology from the military-industrial complex to commercial industry, where the economics and scalability of mass production can offset the costs and time to manufacture large numbers of military articles (Ruttan, 2006). Over time, the spillover effects of these technologies, increased specialization of the military market, and the dramatic growth of demand for commercial technology have led to a disconnect between private sector innovation and the defense market. Today, even as the threat environment is mutating in dangerous and unexpected ways, the DOD is more isolated from its erstwhile civilian partners than ever before. Governments and defense departments globally are no longer able to set the narrative, leading to a diminishing of their influence on driving technological change, while playing catch-up on the adoption front.

By contrast, commercial industry has come to recognize the centrality of product innovation as a basis for competitive differentiation, and has mobilized the entire productive apparatus of the enterprise to achieve this end. Coupled with the democratization of advanced technology and investment capital, this fact has shifted the locus of invention from DOD-backed laboratories to the garages of high-tech entrepreneurs in places like Silicon Valley. At the same time, the substantial regulatory burden assumed by companies transacting with the DOD has had a stultifying effect on business concerns who perceive the military as a secondary market. Other factors, ranging from incompatible product development timescales to increasingly pronounced cultural differences, exacerbate the widening civil-military innovation gap. These gaps, if left unaddressed, can perpetuate and leave the DOD at a disadvantage when it comes to accessing and deploying the latest innovations, whether in product, technology, or process, out into the field. With the dawning realization that the DOD is lagging the commercial state-of-the-art and increasingly those of its adversaries who have adopted innovation paradigms designed to capitalize on these technologies, senior leaders are looking for answers as to how the DOD can maintain and extend the American military's recent history of technological overmatch (Defense Business Board, 2014a). The rapid, inexorable migration of the technological state-of-the-art to the civilian marketplace requires the DOD to fundamentally rethink its relationship with industry or risk falling hopelessly behind adversaries better prepared to accommodate the new military-technology landscape. In a study examining the effectiveness of around 1.29 million defense contract awards issued over seven years, Bresler (2018) found a failure rate of over 50 percent. Several areas were identified that contributed to this problem. These include: (a) DOD's risk-averse culture, which led to "stove-piped" projects characterized by poor internal collaboration and unwillingness to work with new, untested external partners; (b) lack of adequate follow-up and tracking of projects once they were initiated; and (c) insufficient exposure of these initiatives to the broader defense community. Uninterested and uninformed internal DOD customers meant that program 
participants were unwilling to invest in the long term, leading many to exit, and (d) a large portion of the awardees were repeat winners, indicating that those with familiarity and previous experience had a higher chance of being picked again. Bresler (2018), in her study, found that nearly half (48 percent) of program applicants receive only 2 percent of contract awards. In order to improve the chances at success, there needs to be a radical change in how external ideas are accessed and synthesized at the DOD beyond traditional efforts. Successfully aligning the DOD with the imperatives of the modern high-tech marketplace means engaging industry on industry's terms - a radical departure from the traditional monopsony around which Pentagon acquisition practices have evolved. Recent developments suggest that DOD leadership understands this point.

We believe that this critical situation also presents a unique and timely opportunity for the development of a robust innovation ecosystem that promotes the development of entrepreneurs in relation to DOD to gain and sustain a competitive advantage. Governments must discover how to nurture and tap into relevant innovative and entrepreneurial competencies and resources wherever they are found - in the firm and outside the firm; in large firms and in startups; and in the advanced world and in the emerging world. Such enterprises must then encourage entrepreneurs to develop new products and services on an on-going basis to prosper and grow. While the focus and emphasis of for-profit business initiatives can be radically different, there is ample room to co-opt many of the advances made in the private sector to address critical problems faced in the defense sector. By capitalizing on distributed sources of innovation, and placing an emphasis on speed, flexibility and rapid iterations, outside innovators are not just disrupting the behemoths of corporate America, they are also changing the underlying capability development approach of entities like the DOD. Given the prominent, and perhaps decisive role that technology plays in the modern economic and security landscape, the cultivation of entrepreneurial innovators who can rapidly, cost-effectively, and continuously recognize the value-creating applications of technology in a national security context is an existential imperative. In the current entrepreneurial economy, it is expected that the government's role will no longer be one of a "coach on the sidelines", content to set strategies and call initiatives into action, but rather be one of the players executing the collective strategies of education, innovation and entrepreneurship. In short, government must shed its purely bureaucratic role and "lead by example" by becoming more entrepreneurial. These objectives mean that the DOD needs to radically reimagine its role as a practitioner, enabler and advocate for innovation. One major area of concern is the ability to create and sustain an agile and innovative workforce. The size, complexity and diversity of the defense enterprise adds another layer of challenges when it comes to motivating and coordinating both the workforce and external partners 
to respond to the innovation imperatives facing the US military. Creating the right organizational mechanisms and structures to encourage collaboration and innovation, incentivizing innovation in individuals and groups, and reducing bureaucratic overhead are all critical to achieving long-term success.

On 15 November 2014, US Secretary of Defense Chuck Hagel in his keynote address at the Reagan National Defense Forum announced a Defense Innovation Initiative (DII) that would rely in part on "firms and academic institutions outside of the DOD's traditional orbit" to "change the way we innovate, operate, and do business" (DOD DII, 2014). Secretary Hagel's announcement was followed in April 2015 by the introduction of two pilot projects. First, the Defense Innovation Unit Experimental, a DOD “outreach presence” in Silicon Valley, "will focus on scouting emerging and breakthrough technologies and building direct relationships with DOD." Second, the Pentagon, in partnership with the Central Intelligence Agency's venture outfit, In-Q-Tel, will make equity investments in startups developing technologies relevant to the military (Tucker, 2015). These initiatives join a portfolio of recent DOD efforts predating the DII, including Technology Domain Awareness and Better Buying Power 3.0 that seek to furnish the DOD with expanded access to the civilian high-tech marketplace (Winnefeld, 2014).

As heralded by the DII and the associated Third Offset strategy, which concerns reinventing the "process of harnessing innovation to meet new enemies wherever and whenever they arise," the DOD is compelled to find new ways to collaborate with its internal and external constituents and capitalize on the global marketplace of ideas (Coletta, 2017). The launch of the DII signaled an inflection point in the trajectory of military capability development - from the DOD as a producer of innovation to a consumer of innovation. Implicit in this shift is the recognition of the need to "identify, develop and field breakthrough technologies and systems that sustain and advance the capability of US military power" through a new long-range research and development planning program (LRRDP) (Department of Defense, 2014). In 2016, the Defense Innovation Board (DIB), an outgrowth of the DII, was established to advise department leaders on innovation in the public and private sectors, with a view to creating synergies between the department, academia, and commercial industry. The DIB outlined a number of cross-functional priorities to realize the Third Offset strategy, as part of a major rethinking of how the department approaches innovation. The key priorities included: (1) appointing a DOD Chief Innovation Officer to coordinate, oversee and synchronize innovation activities across the department; (2) building a culture of evidence-based, outcome-driven policies and experimentation through personnel policies and incentives; (3) establishing an institute for studying artificial intelligence and machine learning; (4) increasing the speed and timeliness of acquisition processes by using waivers and offering incentives for quickly resolving concerns; (5) increasing invest- 
ment in small, agile, innovative organizations and creating more connections among them; and (6) establishing a computer science resource, a "human cloud" of computer programmers and software developers who would be available on demand to solve software problems swiftly (Pellerin, 2016). The Department has also created a special office (the Strategic Capabilities Office (SCO) to provide a platform for pivoting advanced technologies from the military and civilian sectors to the most challenging (and sensitive) national security problems. As is evident, these priorities were intended to be broad and directional, but also contain specific recommendations. The approach taken is very different from that of normal planning processes. A recent paper refers to it as a case of "metagovernance" (Christiansson, 2018), which challenges "rational planning as it entails an indirect approach of organizing arenas for networks, in which start-up companies and civilian corporations get to interact with government officials in order to identify incrementally suitable acquisition projects." Such a focus on technological research and innovation aims to avoid "surprises" that may compromise national security, and it makes the performance in the scientific and technological areas fundamental (Saunders et al.,1995).

In this book, we seek to examine the new competitive realities confronting DOD and the associated imperatives for innovation - with a view on how to evaluate current and future activities. Through interviews, focused case studies (drawn from the DOD, university and industry contexts, and the international military community), and other primary and secondary research on key stakeholders, we seek to provide decision makers with a framework and tools to better navigate the innovation challenge confronting the US defense enterprise. While the focus and source materials of our research are primarily in the defense domain, we believe that the insights derived from our analysis are relevant to any large, industrial-scale organization seeking to navigate the technological uncertainty implicit in the contemporary landscape.

\subsection{KEY OBJECTIVES AND DESCRIPTION OF OUR STUDY}

The purpose of this book is to take a closer look at the issue of innovation as it is conceptualized, institutionalized and practiced in the DOD, including its attitudes, perceptions and behaviors related to how the DOD expresses innovation; its interactions with internal and external stakeholders as it seeks to be more innovative; and its approach to defining and building innovation competencies associated with human capital development, organization and business practices. We will also examine how the DOD has evolved in its use of internal and external R\&D and commercialization, and how it has developed initiatives to create, scale and deploy innovative solutions to assist in its missions. In 
particular, we examine the evolving strategy towards fourth industrial revolution (4IR) technologies, many of which are originating outside the sphere of influence of the DOD, but are highly relevant to its future applications. These include technologies like artificial intelligence, machine learning and robotics, additive manufacturing, and the changing nature of decision making at the human-machine interface. In this book, we review the emerging landscape of 4IR technologies, describe key developments in their application both in the military and civilian domains, and discuss possible adoption trajectories for specific technologies in the future.

During our multi-year study, we interviewed key decision makers within and outside the DOD as well as several leading thinkers and policy analysts who deal with the issue of innovation in national security and related contexts on a daily basis. In addition, we conducted additional secondary research to validate different perspectives and discover new trends that would further shed light on the phenomenon. Our research methodology, findings and implications are described in future chapters. Our expectation is that, by the end of this book, the reader will arrive at a better understanding and appreciation of the complex, dynamic, multifaceted, interdisciplinary and human-centered implications of innovation in the DOD. We seek to develop and provide tools and recommendations based on our research to guide policy makers and practitioners involved in creating and shaping the defense innovation ecosystem of the future.

\subsection{NATIONAL DEFENSE INNOVATION LANDSCAPE}

Innovation - the exploitation of technology and knowledge to increase value for markets, organizations, not-for-profit sectors, society at large and other venues - is a critical component of societal and economic change and progress. The innovation landscape in national defense has been described as having three distinct regions: products, such as airplanes, tanks, ships; processes, such as integrated systems; and retrofits of legacy systems (Bracken et al., 2005). While the importance of technology to military competitiveness is a broadly accepted fact, somewhat less recognized is the role that the DOD has played in catalyzing the emergence of technology-based products with broad social and economic impact. Moretti et al. (2014) identify a strong correlation between defense research and development investment and private research and development outputs. Moreover, many of the foundational general-purpose technologies upon which the global high-tech economy is based, such as interchangeable parts and mass production, aircraft, nuclear energy, semiconductors, the Internet, and space technology are directly linked to military procurement activities (Ruttan, 2006). Draca (2013) attributes a sharp increase 
in US corporate research and development spending in the 1980s to high DOD technology investment during the administration of President Ronald Reagan. Draca (2013) likewise shows a corresponding deceleration in private research and development coincident with the post-Cold War defense drawdown under Presidents George H.W. Bush and Bill Clinton.

Today's military-industrial complex and commercial industry alike are subject to continuous business process and technology disruption. Since the industrial revolution, military strength and technological development have mirrored one another, and leadership in a technological revolution always coincides with leadership in military strength. The Nobel Prize winning economists Robert Solow and Paul Romer posit that innovation is the result of talent and R\&D, which are part of an intricate network that sets the pace for innovation (Romer, 1989; Solow, 1956). In particular, the interaction of talent and R\&D capacity have a multiplicative effect, the magnitude of which is dependent upon the network's capacity for talent to be applied to R\&D. The futurist Ray Kurzweil (2004) describes this phenomenon, where technology evolution "advances (at least) exponentially" driven by "human ingenuity combined with ever changing market conditions," as the Law of Accelerating Returns. Within this context, succeeding generations of technologies interact in a multiplicative manner to produce a cascading flow of future innovations. Moreover, individuals and small teams enabled by the proliferation of emerging creative technologies play an increasingly significant role in accelerating innovation. Early nineteenth-century military philosopher and strategist Carl von Clausewitz (1976) famously wrote on a concept he referred to as "military genius": the qualities of mind enabling a military professional to recognize and exploit opportunity from the chaos of conflict. A Prussian officer who served during the march of post-revolutionary France across Europe, Clausewitz idealized Napoleon as the archetypal military genius who combined a competitive, martial spirit with elements of character and modern scientific reasoning to devastating effect. Importantly, Clausewitz recognized that developing military genius in a systematic and deliberate manner was an impossibility; however, nations could influence the underlying cultural, intellectual and social conditions that tend to promote the emergence of military genius (Von Clausewitz, 1976). Fast forward to the current epoch, and the qualities that Clausewitz attributed to the military genius are much in evidence in the new class of entrepreneurial innovators disrupting industries and changing the global economy. Today's technology and business innovators are adept at recognizing gaps and opportunities (i.e. signals) amidst the chaos of the competitive environment (i.e. noise) and at moving quickly and efficiently to seize the momentum with new products and services. Entrepreneurs of this stripe are not made in the way in which doctors, engineers and lawyers are developed nor are they motivated to act in response to carefully calculated, 
top-down corporate strategy. People such as these emerge as a result of and in response to environmental conditions present in innovation ecosystems a combination of economic assets, networking assets and physical assets that facilitates the transfer and application of knowledge and associated technology value creation (Katz and Wagner, 2014). In addition, they are focused on speed of execution first and foremost, even if it means that the first few iterations of their product or service offering look like prototypes. In the event that their early efforts start to gain traction, such outcomes can lead to significant disruptions (if not an existential crises) for large and established enterprises who are simply not wired to approach innovation in the same way.

Related to the new competitive dynamics of innovation in the market place, Anderson (2006) links the diversification of the consumer media marketplace to the democratization of the tools of digital content production and distribution (i.e., placing the tools of creation in the hands of consumers). Schwab (2017) defines the shift from traditional forms of industry-led research and development to more local-scale, entrepreneur-led forms as the Fourth Industrial Revolution. According to this paradigm, talent, more than capital, represents the critical factor of innovation, where people "connected by mobile devices, with unprecedented processing power, storage capacity, and access to knowledge" disrupt entire industries as well as traditional power relationships in society. In other words, innovation itself has become decentralized, democratized and accelerated, and significant advantages can accrue to the players who are an integral part of these dynamics. In the future, businesses and militaries that rely on technology for competitive advantage will depend on the cultivation of people who continuously invent and apply value-creating technology interventions. To the extent that individual and small-team actors outside of the traditional corporate context are not constrained by sunk costs, legacy markets and organizational inertia, they are able to efficiently explore the technology-application decision space. This phenomenon is enabled by the aforementioned democratization of technology associated with the widespread expansion of knowledge and creative tools (Friedman, 1999; von Hippel, 1986). Christensen (1997) defines disruptive innovation as the discovery of new products that disrupt markets and the firms that lead those markets. Ries (2011) identified entrepreneur-led startups that target emerging or underserved markets as a key source of disruptive innovation. Within this context, startups develop minimum viable products, observe the customer response to these products, and develop and deploy subsequent generations of products in rapid succession until an optimum value proposition is achieved.

A military example underscoring the impact of disruptive innovation instigated by networks of individuals and based on rapid, iterative product development cycles is the Improvised Explosive Device (IED) threat that appeared in Iraq and Afghanistan beginning in 2003 (Cordesman et al., 2010). Based 
on US government data compiled by iCasualties.org, IEDs were responsible for the majority of coalition combat fatalities in Afghanistan and Iraq. Costing on the order of tens to hundreds of dollars per device to manufacture, IEDs, as the name implies, are improvised from materials on hand augmented with electronic triggers re-purposed from consumer electronics. While opinions vary, it is generally accepted that one of the main challenges in mitigating the IED threat is their lack of standardization combined with an evolutionary cycle that measures in weeks to months. In the cases of Iraq and Afghanistan, almost as soon as the US military deployed a threat-specific IED countermeasure through traditional development channels, new IED variants would appear on the battlefield, rendering the countermeasure obsolete. Revill (2016) identifies specific factors related to the nature of IEDs that have contributed to the diffusion and disruptive adaptation of the technology. Singer (2012) and others note that the Pentagon has spent in the range of $\$ 60$ to $\$ 100$ billion on various counter-IED capabilities since 2003, an investment that has funded such mission-specific products as the massive Mine Resistant Ambush Protected (MRAP) vehicles, radio controlled IED jamming devices, and a legion of IED detection systems. By contrast, the manufacture of IED components, underwritten primarily by diversified commercial markets and adapted for use by networks of individuals in direct contact with the application space, benefit from economies of scale and rapid product development and improvement cycles. This competitive asymmetry means that America's non-state adversaries can produce IEDs at a small fraction of the cost and time associated with the US military's development of countermeasures. This example illustrates to dramatic effect the need to radically change the established institutional mindset and response patterns to counter such disruptive threats.

Another example concerns the use of Artificial Intelligence (AI) in warfare. Brose (2019) emphasized how a coming AI race has frequently been portrayed as a perilous trend capable of reshaping the character of international security. Frank Hoffman of the National Defense University believes that the employment of military capabilities incorporating AI makes warfare less about human willpower, and points to a future where outcomes of combat could be decided by the quality of algorithms (Hoffman, 2018). According to the Pentagon's Defense Science Board, autonomous systems would be capable of working things out as they observe, deciding from several on-the-spot courses of action (The Economist, 2018). The key to efficacy will be the fidelity and timeliness of an autonomous weapons system's understanding of its world. While we are still at the early stages of the AI revolution, the revolutionary implications of this technology for national security have caused the DOD to take notice. Former Deputy Secretary of Defense Patrick Shanahan issued a memorandum on 27 June 2018 that established the Joint Artificial Intelligence Center (JAIC) based on the recommendation of the Defense Innovation Board (Leung and 
Fischer, 2018). While experts opine that general AI (i.e., when AI will be able to reason, plan, problem solve, abstract, and learn from experience) is still years to decades in the future, there are already several practical military applications of narrow AI today. Narrow AI is much more focused and purposefully designed. Robert Work, former Deputy Secretary of Defense in the Obama Administration and one of the architects of the Third Offset Strategy, posited that human-machine collaboration and "combat teaming" of unmanned and manned systems are the future of artificial intelligence adoption in the military. AI will be able to react faster than humans to threats, both physical and electronic, and relieve military analysts of the burden of analyzing large amounts of surveillance data. Possible applications include AI-enabled drones flying alongside piloted aircraft, responding automatically to unexpected changes. Autonomous units also have the advantage of being cheaper, more durable and more reliable than their manned counterparts. Such considerations dramatically alter how the military complex needs to think about the future development of military systems and associated technology investments. Needless to say, the human aspects are also critical, as the role of the human operator and combatant is changing rapidly with the changes in technology. There are significant challenges and questions as to the nature and role of human intervention along practical, ethical and policy lines, as well as concerns about adversaries who may not resort to this critical step in the future.

As the locus of innovation for key technologies like AI has shifted from military labs to the civilian sector, the DOD has taken steps to engage the marketplace through the formation of organizations like the Defense Innovation Unit (DIU). DIU and similar efforts represent an important development in the DOD reaching out beyond its traditional areas of comfort or competence in order to better incorporate the latest cutting-edge technologies that may have developed independently in the commercial sector. Through its locations in the technology hotspots of the US, namely Silicon Valley, Boston and Austin, DIU has the explicit aim of breaking down barriers between the commercial sector and the DOD, and thus improving the ability to acquire technologies developed on the outside (Harper, 2016). However, engaging firms beyond the traditional DOD orbit is only part of the solution to the DOD innovation riddle. Ultimately, the DOD's success as an innovating organization depends on its ability both to inculcate a spirit of innovation and discovery deeply within the defense workforce and to develop the tools and techniques required to express the innovation competence. Towards this end, the DOD has started paying close attention to the role of organizational culture and structure, the need for harnessing individual and group creativity and problem-solving, and providing degrees of freedom to enable out-of-the-box thinking. One concrete outcome of this push, for example, was the establishment of the MD5 National Security Technology Accelerator (MD5) initiative, which was tasked with 
building an entrepreneurial national security workforce by: (a) providing academic programming on topics related to entrepreneurship and innovation; (b) establishing a technology and knowledge transfer platform to facilitate new venture creation; and (c) creating business accelerator services to encourage DOD employees and their peers in academia and industry to create startups based on emerging technology-market opportunities. Such efforts complement the external-facing activities that include reaching out to innovative startups in the wider marketplace, and matching them to specific DOD stakeholders. A second generation of post-DII efforts is now emerging to internalize these and similar innovation practices in the military services. At this point, the central question concerns how such efforts should be appropriately integrated with the culture and business practices of the DOD to achieve the desired effect, namely, enhancing the speed and resilience of the US defense enterprise in the face of persistent, accelerating technological change.

\subsection{STRUCTURING OUR APPROACH}

The remainder of the book is organized as follows. In Chapter 2, we provide a historical overview of innovation, with particular reference to how it is conceptualized and practiced within the US Department of Defense. We introduce the idea of innovation ecosystems, and describe their critical components and characteristics. In Chapter 3, we examine the major innovation challenges facing the US Department of Defense. In particular, we consider the leading edge technology paradigms of the Fourth Industrial Revolution and how they have shaped thinking and action from the innovation perspective. These include robotics, AI and autonomous deep learning systems, miniaturization (with a particular emphasis on nanotechnology), big data analytics, advanced manufacturing technologies, manned-unmanned teaming, and network-enabled semi-autonomous and autonomous weapons systems. These technologies offer the promise of interdisciplinarity, convergence and integration; however, their successful adoption requires a radical rethink in how the innovation organization and the ecosystem around it are structured. Through focused examples and mini case studies, we describe specific projects and organizational approaches that are being used to address these challenges at the leading edge. In Chapter 4, we describe the defense innovation cycle, and how the concepts of transilience and absorptive capacity can play key roles in implementing successful change. We then develop a competency-based framework that can be adapted for fostering innovation. These include the competencies of opportunity development, championing, resource leveraging and location leveraging. In Chapter 5, based on our interviews with key stakeholders as well as focused case studies, we describe how these competencies and combinations thereof have been successfully deployed within specific 
parts of the defense ecosystem. We then describe our main focus case subjects: Defense Advanced Projects Research Agency (DARPA), Defense Innovation Unit (DIU), and AAL (Army Applications Laboratory). In addition to these primary organizations, we also studied initiatives like NSF Innovation Corps, MD5 National Security Technology Accelerator, and Hacking for Defense, among others. In Chapter 6, we describe the implications of our findings for innovation practice at the US Department of Defense. We summarize the key contributions of our research, and provide potential directions for future investigations. We offer a set of recommendations aimed at creating new innovation pathways, ramping up training and educational efforts, leveraging distributed networks and public-private partnerships for innovation, and the new implications of convergence. We conclude by proposing some new avenues for future research and implementation in the new age of defense innovation. 